\title{
Avaliação da idade de corte de dois cultivares de amoreira nos desempenhos biológico e produtivo do bicho-da-seda (Bombyx mori L.)
}

Evaluation of the developmental phases of two mulberry cultivars in the biological and productive performance of the silkworm (Bombyx mori L.)

Evaluación de la edad de corte de dos variedades de morera en los desempeños biológico y productivo del gusano de seda (Bombyx mori L.)

\section{Antônio José Porto'; Sílvia Regina Cunha Funari²; Sílvia Maria Alves Gomes Dierckx³}

Unidade de Pesquisa e Desenvolvimento de Gália. Polo Regional Centro Oeste, Agência Paulista de Tecnologia dos Agronegócios da Secretaria de Agricultura e Abastecimento do Estado de São Paulo (UPD/ APTA/SAA). Gália, SP, Brasil

\footnotetext{
${ }^{1}$ Mestre em Zootecnia. Pesquisador Científico da Unidade de Pesquisa e Desenvolvimento de Gália. APTA/SAA do Estado de São Paulo. CRMV-SP 941/Z ${ }^{2}$ Engenheira Agrônoma. Docente do Departamento de Produção e Exploração Animal da Faculdade de Medicina Veterinária e Zootecnia da Universidade Estadual Paulista, Botucatu, SP

${ }^{3}$ Docente do Departamento de Produção e Exploração Animal da Faculdade de Medicina Veterinária e Zootecnia da Universidade Estadual Paulista, Botucatu, SP. CRMV-SP 234/Z
} 


\section{Resumo}

Objetivo: Avaliar o desempenho do bicho-da-seda quando alimentado com cultivares de amoreira em diferentes idades de corte. Material e Método: Desenvolvido na Unidade de Pesquisa e Desenvolvimento de Gália, SP, da Agência Paulista de Tecnologia dos Agronegócios da Secretaria de Agricultura e Abastecimento do Estado de São Paulo, no período de 31/12/1997 a 06/05/1998. O experimento foi iniciado com lagartas do Bombyx mori L., no $3^{2}$ ínstar, alimentadas com dois cultivares de amoreira (IZ 56/4 e Korin) em quatro idades de corte (7, 10, 13 e 16 semanas), sendo analisados, no $5^{\circ}$ ínstar, caracteres biológicos e de produção de casulo. Resultados: Quando foi analisado cada cultivar de amoreira nas diferentes idades de corte, observaram-se, para os caracteres biológicos, variações somente para peso vivo (PV) e ganho de peso (GP) das lagartas. Dos caracteres produtivos estudados, variou apenas o peso de casca sérica (PCS), quando proveniente de lagartas alimentadas com o cultivar Korin. Quando se compararam os cultivares em cada idade de corte, apenas foram observadas variações para os caracteres biológicos PV e peso de crisálida (PCr) e para os caracteres produtivos peso de casulo (PC), PCS e número de casulos formados (NC). Conclusões: As lagartas apresentaram bom PV, no $5^{2}$ ínstar, quando receberam no $3^{2}$ e $4^{\mathcal{Q}}$ ínstares folhas de ambos os cultivares de amoreira com idade de corte próxima a dez semanas, embora tenham apresentado melhor GP quando alimentadas com folhas de plantas em idade de corte mais avançada (acima de dez semanas). A variável porcentagem de seda líquida (PSL) pouco foi influenciada pelos tratamentos, assim como o $\mathrm{NC}$ em relação à idade de corte da planta. O cultivar Korin, no geral, propiciou ao bicho-da-seda melhores desempenhos biológico e produtivo.

Palavras-chave: Nutrição animal. Bichos-da-seda, crescimento e desenvolvimento. Morus.

\section{Introdução}

A amoreira (Morus sp.) é uma planta perene com uma boa produção de massa verde, cujas folhas constituem único alimento do bicho-da-seda (Bombyx mori L.), fornecendo todos os elementos nutricionais para seu crescimento e desenvolvimento. Dessa forma, supõe-se que toda variação dos constituintes da folha afete a nutrição da lagarta e conseqüentemente a produção de seda, assim como observado em alguns estudos. ${ }^{1-6}$

Os conteúdos da folha de amoreira variam muito sob efeito de fatores internos e externos como: fotoperíodo e estações, textura e condições de fertilização do solo, efeitos de manejo como tipo de condução da planta, hora de colheita das folhas, condições de armazenamento, além dos cultivares utilizados, da posição e maturidade das folhas (PANGCHUAN; DA-CHUANG, ${ }^{7}$ 1992).

De um modo geral, o crescimento das plantas segue um período, com etapas teoricamente definidas. Voisin $^{8}$ (1971) descreveu a curva de crescimento de uma planta após o corte, ou curva da rebrota, como tendo forma sigmóide, assim como a curva biológica universal do crescimento de todos os organismos vivos, podendo-se distinguir três etapas que, unidas, formam o período total do crescimento. Desse modo, a primeira etapa é a de crescimento lento, às custas das reservas, sem células clorofiladas e, portanto, sem fotossíntese; a segunda etapa é representada por um período de crescimento muito rápido, com a presença de folhas, células clorofiladas e fotossíntese; e a terceira etapa, ou período final, é de escasso crescimento, estando a planta próxima da fase reprodutiva.

As duas etapas finais da curva - nas quais há, primeiramente, uma intensa atividade fotossintética e um grande crescimento de massa vegetal e, posteriormente, um acúmulo de reservas para iniciar a etapa reprodutiva - têm sido objeto de estudo de inúmeros pesquisadores da área de nutrição animal que buscam a idade de corte em diversas espécies forrageiras, em que os elementos e a textura, principalmente das folhas e caules, reflitam em uma máxima qualidade desse material como alimento. 
Em amoreira, variações dos componentes da folha em função do desenvolvimento da planta são descritos nos trabalhos de Dechen et al. ${ }^{9}$ (1973); Qader et al. ${ }^{10}$ (1991) e Bongale et al. ${ }^{11}$ (1997), os quais demonstraram a importância do manejo adequado da poda da amoreira, regulando a idade de corte da planta, a fim de obter folhas com alto valor nutricional para alimentação das lagartas. Fonseca et al. ${ }^{12}$ (1972), quando avaliaram o cultivar Catânia 1 em três idades de brotação (um, dois e três meses), sobre caracteres de peso de casulo e peso de lagarta, concluíram que as folhas com um mês de brotação possibilitaram resultados estatisticamente superiores aos demais tratamentos. Assim, os autores sugeriram o uso de folhas de amoreira tanto mais novas quanto possível, levando em consideração o desenvolvimento do ramo e a produção de folhas do amoreiral.

No entanto, Hanada e Watanabe ${ }^{13}$ (1986) preconizaram como ideal o uso de folhas que apresentassem um período de crescimento de 75 a 90 dias, considerando que aquelas imaturas apresentam rápido crescimento, alto teor de líquido e reduzido teor de nutrientes. Magário ${ }^{14}$ (1993), estudando a composição bromatológica do cultivar de amoreira Yamada em várias idades de crescimento, concluiu que a melhor época de corte para se fornecer às lagartas do bicho-da-seda foi aos 67 dias de crescimento, após a poda de uniformização. Porto ${ }^{15}$ (1997) e Porto et al. ${ }^{16}$ (1998) observaram que, de quatro cultivares de amoreira de grande aceitação no meio produtivo, dois (IZ 56/4 e IZ 40) apresentaram melhores resultados de produção de casulo quando fornecidos às lagartas de $5^{\circ}$ ínstar com idade de corte na faixa de 90 dias, ao passo que os cultivares IZ 10/4 e Korin revelaram melhores resultados quando fornecidos com aproximadamente 70 dias de desenvolvimento, demonstrando a importância da adequação do manejo de poda, conforme o cultivar disponível.

Dessa maneira, com o objetivo de analisar alguns caracteres biológicos e de produção de casulo do bicho-da-seda, quando alimentado com dois cultivares de amoreira em quatro idades de corte, o presente estudo foi conduzido.

\section{Material e Método}

Para o desenvolvimento deste experimento foram utilizadas as dependências da Unidade de Pesquisa e Desenvolvimento (UPD) de Gália, SP, Polo Regional Centro Oeste da Agência Paulista de Tecnologia dos Agronegócios da Secretaria de Agricultura e Abastecimento do Estado de São Paulo (APTA/SAA), situada na latitude $22^{\circ} 18^{\prime}$ sul e longitude $45^{\circ} 33^{\prime}$ oeste.

Foi reservada uma área de amoreiral com cerca de $860 \mathrm{~m}^{2}$ e aproximadamente dez anos de plantio, composta por dois cultivares (IZ 56/4 e Korin), escolhidos em virtude de suas características de produção de folhas e adaptação, tendo boa aceitação no meio sericícola. Os tratos culturais seguiram as recomendações técnicas normais, com calagem e adubação baseadas na análise de solo, de acordo com Okino $^{17}$ (1982). Cada área de amoreiral, conforme o cultivar $\left(430 \mathrm{~m}^{2}\right)$, foi dividida em quatro talhões com as seguintes subáreas: talhão $1-70 \mathrm{~m}^{2}$, talhão $2-80$ $\mathrm{m}^{2}$, talhão $3-120 \mathrm{~m}^{2}$ e talhão $4-160 \mathrm{~m}^{2}$. As podas dos respectivos talhões de amoreira foram realizadas em datas diferentes, para a obtenção de períodos +defasados no desenvolvimento da planta. Assim, para a obtenção da $1^{\mathrm{a}}$ idade de corte -16 semanas (talhão 1) - poda em 31/12/1997; para obtenção da $2^{\mathrm{a}}$ idade de corte - 13 semanas (talhão 2 ) - poda em 21/01/1998; para obtenção da $3^{\text {a }}$ idade de corte 10 semanas (talhão 3) - poda em 11/02/1998; e para obtenção da $4^{\mathrm{a}}$ idade de corte -7 semanas (talhão 4 ) - poda em 04/03/1998.

Amostras de folhas, conforme os tratamentos, foram coletadas, acondicionadas em recipiente térmico e enviadas ao laboratório de bromatologia da Faculdade de Medicina Veterinária e Zootecnia da Universidade Estadual Paulista (UNESP), Campus de Botucatu, SP.

Na sirgaria, os trabalhos experimentais foram iniciados com o alojamento das lagartas do bichoda-seda no início do $3^{\circ}$ ínstar $(11 / 04 / 1998)$ e concluídos com a formação e coleta dos casulos para análises (06/05/1998). A sirgaria experimental era de alvenaria, com telhas de barro e dispositivo de 
controle de ventilação (esteiras móveis). Uma semana antes da chegada das lagartas foi realizada uma desinfecção em todos os equipamentos e instalações, conforme preconizado nos manuais técnicos (FONSECA; FONSECA ${ }^{18}$, 1988). As leituras da temperatura e da umidade relativa do ar no interior da sirgaria foram realizadas diariamente em cada trato, obtendo-se uma média geral no $5^{\circ}$ ínstar de $23,41^{\circ} \mathrm{C}$ e $75,97 \%$, respectivamente.

As lagartas do bicho-da-seda Bombyx mori L. (Lepidoptera: Bombycidae), em início de $3^{\mathfrak{Q}}$ ínstar, foram obtidas de um lote de híbridos comerciais provenientes do Convênio entre a Secretaria de Agricultura e Abastecimento (SAA) do Estado de São Paulo e Prefeitura Municipal de Gália, SP. Foram acondicionadas, em número de 50 , em caixas de madeira de $0,80 \times 0,70 \times 0,03 \mathrm{~m}$, devidamente forradas com papel-jornal.

As folhas de amoreira utilizadas na alimentação das lagartas foram colhidas em dois períodos do dia: nas horas mais frescas da manhã e nas horas mais frescas da tarde. Os tratos foram diferenciados, de acordo com os tratamentos, a partir do $3^{2}$ ínstar e distribuídos em cinco horários: $7 \mathrm{~h}, 10 \mathrm{~h}, 13 \mathrm{~h}, 16 \mathrm{~h}$ e $19 \mathrm{~h}$.

Os aspectos biológicos do bicho-da-seda foram avaliados por: peso vivo médio da lagarta (PV), obtido a partir de pesagens diárias das lagartas durante o $5^{\circ}$ ínstar, em balança eletrônica e posterior determinação do peso médio unitário em gramas; do ganho de peso médio diário da lagarta (GP), obtido pela diferença entre os pesos inicial e final, após um período de alimentação de um dia, sendo os valores dados em miligrama de matéria seca e do peso médio da crisálida ( $\mathrm{PCr})$, determinado pela pesagem de 30 crisálidas em cada parcela, com posterior determinação do peso médio unitário em gramas.

Para avaliação da produção do casulo, foram consideradas as seguintes variáveis: peso médio do casulo (PC), obtido pela pesagem de 30 casulos por parcela coletados ao acaso, com posterior determinação do peso médio unitário em gramas; e peso médio da casca sérica (PCS), obtido a partir dos casulos utilizados na determinação anterior. Após ser cortada para retirada da crisálida e do espólio, a casca sérica foi pesada, determinando-se o peso médio unitário em gramas, e a porcentagem de seda líquida (PSL), tendo sido primeiramente determinada a porcentagem de seda bruta pela seguinte fórmula:

$\%$ seda bruta $=\frac{\text { peso de } 30 \text { cascas séricas }}{\text { peso de } 30 \text { casulos inteiros }} \times 100$

A porcentagem de seda líquida foi obtida descontando-se $24 \%$ da porcentagem de seda bruta, que corresponde às perdas durante o processo de fiação, e número de casulos formados (NC), determinado pela contagem do número de casulos que efetivamente chegaram ao final da fase larval, com transformação da lagarta em crisálida.

$\mathrm{O}$ delineamento experimental adotado foi aquele inteiramente casualizado (DIC), com os tratamentos no esquema fatorial $4 \times 2$ (quatro idades de corte da planta versus dois cultivares de amoreira), com quatro repetições para cada tratamento.

Os resultados obtidos foram submetidos à análise de variância e as médias comparadas pelo teste de Tukey, ao nível de $5 \%$ de probabilidade. Os valores originais de contagem para a variável $\mathrm{NC}$ foram transformados em raiz quadrada de $\mathrm{x}+1$.

\section{Resultados e Discussão}

Um bom ganho de peso na fase larval dos insetos holometabólicos é condição fundamental, pois é nesta fase que armazenam toda energia necessária para a formação do casulo, transformação em crisálida e desenvolvimento do adulto.

Na Tabela 1 estão apresentados os valores médios de algumas variáveis relacionadas com o desempenho biológico do bicho-da-seda, analisados em função da interação entre os fatores cultivar de amoreira e idade de corte da planta. 
Tabela 1 - Peso vivo médio (PV) e ganho de peso médio diário (GP) da lagarta do bicho-da- seda no $5^{\circ}$ ínstar e peso médio da crisálida (PCr), segundo as idades de corte da planta e cultivares de amoreira e respectivos coeficientes de variação

\begin{tabular}{|c|c|c|c|c|c|c|}
\hline \multirow[t]{2}{*}{$\begin{array}{l}\text { Idade de corte } \\
\text { (semanas) }\end{array}$} & \multicolumn{2}{|c|}{$\begin{array}{c}\text { GP } \\
\text { (miligramas } \\
\text { da matéria seca) }\end{array}$} & \multicolumn{2}{|c|}{$\begin{array}{c}\text { PV } \\
\text { (gramas) }\end{array}$} & \multicolumn{2}{|c|}{$\begin{array}{c}\mathrm{PCr} \\
\text { (gramas) }\end{array}$} \\
\hline & $1256 / 4$ & Korin & IZ 56/4 & Korin & IZ 56/4 & Korin \\
\hline 7 & $\begin{array}{c}59,063 \\
\text { a B }\end{array}$ & $\begin{array}{c}69,338 \\
\text { a B }\end{array}$ & $\begin{array}{l}2,375 \\
\text { b A* }\end{array}$ & $\begin{array}{l}2,597 \\
\text { a AB }\end{array}$ & $\begin{array}{c}1,277 \\
\text { b A }\end{array}$ & $\begin{array}{c}1,495 \\
\text { a A }\end{array}$ \\
\hline 13 & $\begin{array}{c}83,508 \\
\text { a A }\end{array}$ & $\begin{array}{c}91,967 \\
\text { a A }\end{array}$ & $\begin{array}{c}2,250 \\
\text { b B }\end{array}$ & $\begin{array}{c}2,627 \\
\mathrm{aAB}\end{array}$ & $\begin{array}{c}1,391 \\
\text { a A }\end{array}$ & $\begin{array}{c}1,512 \\
\text { a A }\end{array}$ \\
\hline 16 & $\begin{array}{c}79,354 \\
\text { a A }\end{array}$ & $\begin{array}{c}85,788 \\
\text { a A }\end{array}$ & $\begin{array}{c}2,113 \\
\text { b C }\end{array}$ & $\begin{array}{c}2,528 \\
\text { a B }\end{array}$ & $\begin{array}{c}1,374 \\
\text { b A }\end{array}$ & $\begin{array}{c}1,525 \\
\text { a A }\end{array}$ \\
\hline
\end{tabular}

*Letras minúsculas diferentes, na linha, indicam diferenças significativas entre cultivares $(\mathrm{P}<0,05)$

Letras maiúsculas diferentes, na coluna, indicam diferenças significativas entre idades de corte $(\mathrm{P}<0,05)$

$* * \mathrm{CV}=$ Coeficiente de variação

No geral, as lagartas de $5^{\circ}$ ínstar apresentaram mais ganho de peso quando receberam folhas de amoreira em idade de corte na faixa de dez a 16 semanas, com tendência para melhores resultados quando alimentadas com folhas de 13 semanas, para ambos os cultivares. No entanto, obtiveram maior peso vivo as lagartas que receberam folhas com menor período de desenvolvimento (aproximadamente dez semanas), variando de sete a dez semanas para o cultivar IZ 56/4 e na faixa de sete a 13 semanas para o cultivar Korin. Quanto ao peso da crisálida, pode-se notar que não houve variação significativa para esta variável, nas diferentes idades de corte em que os dois cultivares foram utilizados, embora haja uma tendência de maiores pesos quando as lagartas receberam folhas com idade de corte mais avançada (13 e 16 semanas).

Como este experimento teve início no $3^{\circ}$ ínstar, já com os tratamentos diferenciados, é provável que as lagartas alimentadas com folhas em menor idade de corte apresentaram um melhor desempenho quanto ao peso corporal, uma vez que as folhas eram de melhor valor nutricional, demonstrado pela análise bromatológica (Tabela 2), em que os valores médios de proteína bruta, matéria mineral e umidade, em geral, decresceram; e os de fibra bruta aumentaram com a elevação da idade de corte da planta. Tais resultados estão de acordo com Dechen et al. ${ }^{9}$ (1973), que descreveram um decréscimo no teor de proteína na folha de amoreira com a idade, tanto na brotação (de 28,4\% aos 30 dias para 19,2\% aos 120 dias, sendo consideradas brotação as plantas com até 120 dias de desenvolvimento vegetativo após poda) como na rebrota (de $27,8 \%$ aos 150 dias para $20,4 \%$ aos 240 dias); com Qader et al. ${ }^{10}$ (1991) que observaram um gradual decréscimo dos teores de umidade e proteína bruta da folha com elevação da maturidade, enquanto os teores de carboidratos solúveis e fibra bruta aumentaram; e com Bongale et al. ${ }^{11}$ (1997), que estudando a qualidade nutritiva da folha de 14 cultivares de amoreira, associada com diferentes estágios de crescimento, observaram um decréscimo dos conteúdos de umidade e proteína com o aumento da maturidade. 
PORTO, A. J.; FUNARI, S. R. C.; DIERCKX, S. M. A. G. Avaliação de dois cultivares de amoreira no desempenho do bicho-da-seda. Evaluation of two mulberry cultivars in the performance of the silkworm. / Evaluación de dos variedades de morera en el desempeño del gusano de seda. Rev. Educ. Contin. CRMV-SP/Contin. Educ. J. CRMV-SP, São Paulo, v. 7, n. 1/3, p. 55-65, 2004.

Tabela 2 -Análise bromatológica de folhas de dois cultivares de amoreira em quatro idades de corte: média de três análises*

\begin{tabular}{ccccccc}
\hline Cultivar & $\begin{array}{c}\text { Idade } \\
\text { de corte } \\
\text { (semanas) }\end{array}$ & MS(\%) & PB(\%) & EE(\%) & MM(\%) & FB(\%) \\
\hline \multirow{2}{*}{ IZ 56/4 } & 7 & 22,79 & 27,01 & 2,53 & 10,59 & 8,22 \\
& 10 & 23,52 & 23,14 & 3,76 & 8,73 & 9,23 \\
& 13 & 26,37 & 21,59 & 2,97 & 7,89 & 8,65 \\
& 16 & 25,83 & 20,30 & 4,27 & 8,83 & 9,56 \\
Korin & 7 & 22,41 & 27,13 & 3,42 & 10,35 & 8,09 \\
& 10 & 22,89 & 23,72 & 4,56 & 7,38 & 8,69 \\
& 13 & 23,85 & 23,21 & 4,91 & 6,54 & 8,53 \\
\hline
\end{tabular}

* Resultados expressos em $100 \%$ da matéria seca

$\mathrm{MS}=$ Matéria seca; $\mathrm{PB}=$ Proteína bruta $; \quad \mathrm{EE}=$ Extrato etéreo $; \quad \mathrm{MM}=$ Matéria mineral $; \quad \mathrm{FB}=$ Fibra bruta

Para Crocomo e Parra ${ }^{21}$ (1985) o conteúdo de água, o conteúdo de proteína e o teor de fibra da planta afetam a eficiência de conversão do alimento em biomassa no inseto. Conforme Ishaaya ${ }^{19}$ (1986), a redução do conteúdo de proteína na dieta artificial - de 7,6 para 3,6\% - resultou em um decréscimo de cerca de $75 \%$ nas atividades proteolítica e amilolítica da parede intestinal, com um similar decréscimo observado no peso da lagarta de Spodoptera littoralis.

Paul et al..$^{20}$ (1992), estudando o impacto da umidade da folha de amoreira sobre o desempenho de lagartas do bicho-da-seda no $5^{9}$ ínstar, constataram que o peso final da lagarta aumentou significativamente com a elevação da água na folha, mostrando uma alta correlação positiva. Também Chaluvachari e Bongale ${ }^{1}$ (1995) associaram os maiores pesos larvais do bicho-da-seda com folhas de maior conteúdo de umidade, bem como pela proporção de açúcar/proteína mais baixa em alguns cultivares de amoreira.

Por intermédio dos dados apresentados na Tabela 3, é possível verificar que as lagartas alimentadas de folhas com idade de corte de sete e dez semanas iniciaram o $5^{\circ}$ instar com pesos corporais acumulados, em geral, superiores àquelas alimentadas com folhas em idade de corte mais avançado e, mesmo apresentando menor ganho de peso no último ínstar, ainda assim mantiveram na média, pesos corporais maiores. No entanto, este quadro não se refletiu em crisálidas mais pesadas, podendo-se notar até mesmo valores numéricos superiores nos tratamentos em que foram utilizados os cultivares com 13 e 16 semanas.

Tabela 3 - Peso vivo (médias em gramas) de lagarta do bicho-da-seda no início do $5^{\varrho}$ ínstar, segundo as idades de corte de dois cultivares de amoreira

\begin{tabular}{|c|c|c|}
\hline \multirow{2}{*}{$\begin{array}{l}\text { Idade de corte } \\
\text { (semanas) }\end{array}$} & \multicolumn{2}{|c|}{ Cultivares } \\
\hline & IZ $56 / 4$ & Korin \\
\hline 7 & $1,143 \mathrm{~b} \mathrm{~A}^{*}$ & 1,233 a $B$ \\
\hline 10 & $1,161 \mathrm{~b} \mathrm{~A}$ & 1,308 a $\mathrm{A}$ \\
\hline 13 & 1,046 b B & 1,206 a B \\
\hline 16 & $1,066 \mathrm{~b}$ B & 1,183 a B \\
\hline
\end{tabular}

*Letras minúsculas diferentes, na linha, indicam diferenças significativas entre cultivares $(\mathrm{P}<0,05)$

Letras maiúsculas diferentes, na coluna, indicam diferenças significativas entre idade de corte $(\mathrm{P}<0,05)$ 
Estes resultados vêm confirmar o que preconiza a técnica, sendo recomendada a utilização de folhas mais novas para lagartas do $1^{\varrho}$ ao $3^{ }$ínstares e folhas um tanto mais maduras para lagartas de $4^{\circ}$ e $5^{\circ}$ ínstares. ${ }^{12,19}$

Analisando ainda as Tabelas 1 e 3, ao se comparar os cultivares de amoreira, nota-se que o cultivar Korin proporcionou melhores resultados de peso vivo de lagarta nas quatro idades de cortes testadas, assim como valores numéricos superiores de ganho de peso (Tabela 1), embora não tenha havido variações significativas entre as médias para esta variável. Mendonça ${ }^{4}$ (1994) quando testou alguns cultivares de amoreira com 65 dias de desenvolvimento, na produção de casulos do bicho-da-seda, não encontrou variação no peso das lagartas entre estes dois cultivares (IZ 56/4 - 5,52 g, Korin - 5,06 g).

Uma análise entre os dois cultivares quanto ao peso da crisálida demonstrou que o cultivar Korin proporcionou, em geral, melhores resultados, diferindo estatisticamente quando fornecido com sete e 16 semanas de desenvolvimento. Com dez semanas (cerca de 70 dias de desenvolvimento) - assim como no trabalho de Mendonça ${ }^{4}$ (1994), no qual esses mesmos cultivares foram utilizados com aproximadamente 65 dias -, não houve variação estatística entre eles para esta variável. Os valores encontrados por Mendonça ${ }^{4}$ (1994) foram superiores aos obtidos no presente estudo, em que as crisálidas provenientes do tratamento com o cultivar IZ $56 / 4$ apresentaram peso médio de $1,78 \mathrm{~g}$, e aquelas provenientes do tratamento com o cultivar Korin, peso médio de $1,75 \mathrm{~g}$.

Os valores médios das variáveis relacionadas à produção do casulo, analisadas em função dos tratamentos a que foram submetidas as lagartas, podem ser vistos na Tabela 4 .

Tabela 4 - Peso médio de casulo (PC), peso médio de casca sérica (PCS), porcentagem de seda líquida (PSL) e número de casulos formados (NC) do bicho-da-seda, segundo as idades de corte de dois cultivares de amoreira e respectivos coeficientes de variação

\begin{tabular}{|c|c|c|c|c|c|c|c|c|}
\hline \multirow{3}{*}{$\begin{array}{l}\text { Idade de } \\
\text { corte } \\
\text { (semanas) }\end{array}$} & \multirow{2}{*}{\multicolumn{2}{|c|}{$\frac{\mathrm{PC}}{\text { (gramas) }}$}} & \multirow{2}{*}{\multicolumn{2}{|c|}{$\frac{\text { PCS }}{\text { (gramas) }}$}} & \multirow{2}{*}{\multicolumn{2}{|c|}{$\frac{\text { PSL }}{(\%)}$}} & \multirow{2}{*}{\multicolumn{2}{|c|}{$\mathrm{NC}^{*}$}} \\
\hline & & & & & & & & \\
\hline & IZ 56/4 & Korin & IZ 56/4 & Korin & IZ 56/4 & Korin & IZ $56 / 4$ & Korin \\
\hline \multirow[t]{2}{*}{7} & 1,656 & 1,913 & 0,368 & 0,430 & 16,89 & 17,11 & 6,0 & 6,7 \\
\hline & b A** & a A & b A & a A & a A & a A & b A & a A \\
\hline \multirow[t]{2}{*}{10} & 1,721 & 1,820 & 0,378 & 0,385 & 16,69 & 16,09 & 6,0 & 6,4 \\
\hline & a A & a A & a A & a B & a A & a A & a A & a A \\
\hline \multirow[t]{2}{*}{13} & 1,792 & 1,948 & 0,391 & 0,418 & 16,58 & 16,32 & 6,0 & 6,6 \\
\hline & a A & a A & a A & $\mathrm{a} A B$ & a A & a A & b A & a A \\
\hline \multirow[t]{2}{*}{16} & 1,763 & 1,959 & 0,379 & 0,438 & 16,34 & 16,98 & 6,1 & 6,4 \\
\hline & a A & a A & $\mathrm{bA}$ & a A & a A & a A & $\mathrm{aA}$ & a A \\
\hline CV $(\%)^{* * *}$ & \multicolumn{2}{|c|}{4,60} & \multicolumn{2}{|c|}{3,99} & \multicolumn{2}{|c|}{2,56} & \multicolumn{2}{|c|}{4,20} \\
\hline
\end{tabular}

* Valores transformados em raiz quadrada de $\mathrm{x}+1$

** Letras minúsculas diferentes, na linha, indicam diferenças significativas entre cultivares $(\mathrm{P}<0,05)$

Letras maiúsculas diferentes, na coluna, indicam diferenças significativas entre idade de corte $(\mathrm{P}<0,05)$

$* * * \mathrm{CV}=$ Coeficiente de variação

O cultivar IZ 56/4, embora não tenha apresentado diferença estatística para nenhuma das variáveis relacionadas à produção de casulo, nas quatro idades de corte em que foi utilizado, apresentou valores numéricos de peso de casulo e peso de casca sérica superiores quando fornecido com 13 semanas 
PORTO, A. J.; FUNARI, S. R. C.; DIERCKX, S. M. A. G. Avaliação de dois cultivares de amoreira no desempenho do bicho-da-seda. / Evaluation of two mulberry cultivars in the performance of the silkworm. / Evaluación de dos variedades de morera en el desempeño del gusano de seda. Rev. Educ. Contin. CRMV-SP/Contin. Educ. J. CRMV-SP, São Paulo, v. 7, n. 1/3, p. 55-65, 2004.

de desenvolvimento, resultado este de acordo com os trabalhos de Porto ${ }^{15}(1997)$ e Porto et al. ${ }^{16}$ (1998), que justificaram os resultados pelo programa de seleção desenvolvido no Instituto de Zootecnia, Nova Odessa, SP, em que as características selecionadas para os cultivares foram obtidas de plantas entre 80 e 90 dias de desenvolvimento.

Para o cultivar Korin, apenas quando se analisou o peso da casca sérica pôde-se observar variações entre os tratamentos. Os resultados, no geral, não permitiram definir uma melhor idade de corte da planta para alimentação das lagartas. De acordo com os trabalhos de Porto ${ }^{15}$ (1997) e Porto et al. ${ }^{16}$ (1998), pesos mais elevados de casulo e de casca sérica foram obtidos quando se forneceram folhas do cultivar Korin com 70 dias de desenvolvimento. Para este estudo, no entanto, o tratamento que utilizou o cultivar Korin na mesma idade de corte proporcionou resultados até mesmo inferiores aos demais.

Ao relacionar os resultados deste estudo com valores encontrados na literatura, pode-se observar que os pesos médios de casulo e de casca sérica apresentaram-se, na maioria das vezes, menores. Mendonça ${ }^{4}$ (1994) obteve pesos médios de casulo e casca sérica na ordem de $2,30 \mathrm{~g}$ e $0,517 \mathrm{~g}$ para o cultivar IZ 56/4, e 2,25 g e 0,492 g para o cultivar Korin. Porto $^{15}$ (1997) encontrou valores de $1,93 \mathrm{~g}$ no peso do casulo e $0,429 \mathrm{~g}$ no peso da casca sérica para o cultivar IZ 56/4, e 2,01 g e 0,451 g para o cultivar Korin, em estudo desenvolvido na primavera. Também no trabalho de Porto et al. ${ }^{16}$ (1998), conduzido na estação de outono, os valores foram superiores, tanto para o cultivar IZ 56/4 (PC - 2,29 g, PCS - 0,482 g) quanto para o cultivar Korin (PC - 2,37g, PCS $0,509 \mathrm{~g})$.

A variável porcentagem de seda líquida é muito utilizada na comercialização do casulo, estando diretamente relacionada ao preço do produto. $\mathrm{O}$ seu emprego como parâmetro para avaliação da produção de seda tem sido freqüente em trabalhos de pesquisa. Assim como observado nos estudos de Mendonça ${ }^{4}$ (1994), Porto ${ }^{15}$ (1997) e Porto et al. ${ }^{16}$ (1998), os valores encontrados, tanto nos tratamentos que utilizaram o cultivar IZ 56/4 quanto aqueles que utilizaram o cultivar Korin situaram-se na faixa de 16,00 a $17,30 \%$, sem apresentar diferença estatística entre si.

Para a formação de casulos normais, a sanidade da lagarta e seu completo desenvolvimento são condições básicas. Além das características qualitativas do casulo, a quantidade deles formada reflete bem essas condições, podendo ser considerado um bom parâmetro para avaliar os efeitos de fatores que agem sobre o bicho-da-seda na sua fase larval. Em ambos os.cultivares estudados não houve diferenças entre os tratamentos para esta variável, estando em concordância com os resultados encontrados por Porto ${ }^{15}$ (1997).

Por meio de uma análise comparativa entre os resultados obtidos com os cultivares IZ 56/4 e Korin, nota-se que valores superiores de produção foram encontrados em tratamentos que forneceram folhas do cultivar Korin, principalmente quando comparados com sete semanas de desenvolvimento, momento no qual as diferenças entre os cultivares foram bem maiores.

Mendonça $^{4}$ (1994), quando comparou estes dois cultivares de amoreira, não observou diferenças estatísticas para as médias de peso de casulo, peso de casca sérica e teor de seda. No trabalho de Porto et al. ${ }^{16}$ (1998), embora não se tenha encontrado variação entre o cultivar IZ 56/4 e Korin para essas mesmas variáveis, os valores médios apresentaram-se superiores com a utilização do cultivar Korin, tendência também observada no estudo de Porto ${ }^{15}$ (1997).

Sendo o peso da casca sérica resultado da diferença entre os valores de peso de casulo e peso de crisálida (mais os espólios), pode-se supor que os casulos com crisálidas mais pesadas resultem em cascas séricas de menor peso, no entanto, os casulos produzidos por lagartas alimentadas com folhas do cultivar Korin, geralmente, apresentaram peso de casulo, peso de casca e peso de crisálida (Tabelas 1 e 4) superiores aos casulos produzidos por lagartas alimentadas com folhas do cultivar IZ 56/4, denotando uma eficiente produção de seda com o uso desse cultivar de amoreira. 
PORTO, A. J.; FUNARI, S. R. C.; DIERCKX, S. M. A. G. Avaliação de dois cultivares de amoreira no desempenho do bicho-da-seda. Evaluation of two mulberry cultivars in the performance of the silkworm. / Evaluación de dos variedades de morera en el desempeño del gusano de seda. Rev. Educ. Contin. CRMV-SP/Contin. Educ. J. CRMV-SP, São Paulo, v. 7, n. 1/3, p. 55-65, 2004.

Para a variável número de casulos formados, da mesma forma que observado para peso de casulo e peso de casca sérica, manteve-se uma tendência superior com o uso do cultivar Korin. Mendonça ${ }^{4}$ (1994) não constatou diferença significativa para porcentagem de encasulamento quando comparou os cultivares IZ 56/4 e Korin, com 65 dias de desenvolvimento. Com idade de corte de 70 dias (dez semanas), os resultados relativos ao número de casulos formados mostraram-se similares aos obtidos por Mendonça ${ }^{4}$ (1994).

Em uma análise geral dos resultados, pode-se verificar que, embora as folhas de amoreira nas idades de corte em que foram utilizadas tenham proporcionado modificações nos aspectos fisiológicos das lagartas (PV e GP), tais mudanças não refletiram em grandes variações no peso da crisálida e nos aspectos relacionados à produção do casulo (PC, PCS, PSL e NC), demonstrando uma grande capacidade de adaptação do bicho-da-seda.

Quanto às lagartas de Spodoptera frugiperda, alimentadas com folhas de milho, trigo e sorgo sacarino, Crocomo e Parra ${ }^{21}$ (1985) concluíram que elas apresentaram uma capacidade de compensar as dificuldades de utilização encontradas nos diferentes hospedeiros e manter a performance do desenvolvimento. De acordo com Parra ${ }^{22}$ (1991), uma larva de inseto holometabólico tende a escolher um alimento apropriado para consumí-lo em proporções balanceadas, de tal forma a utilizá-lo adequadamente para promover um ótimo crescimento e desenvolvimento. Nesta escolha estão envolvidas adaptações e estratégias para cada espécie, incluindo a capacidade compensatória em condições inadequadas. Paul et al. ${ }^{20}$ (1992) observaram em lagartas do Bombyx mori L., durante o $5^{\circ}$ ínstar, algumas adaptações no consumo e na utilização do alimento frente ao conteúdo de água na folha, indicando um ajustamento fisiológico das lagartas para um rápido crescimento e transformação para a próxima fase do ciclo.

\section{Conclusões}

- Para a obtenção de lagartas com bom peso corporal no final do ciclo larval é aconselhável que recebam no $3^{2}$ e $4^{2}$ ínstares, folhas dos com idade de corte próxima a dez semanas, considerando os cultivares analisados;

- Para lagartas do bicho-da-seda no $5^{\circ}$ ínstar, a utilização das folhas de ambos os cultivares, nas idades de corte mais avançadas (acima de dez semanas), proporcionou ganho de peso superior;

- A porcentagem de seda líquida não variou em função dos cultivares de amoreira e das idades de corte em que foi utilizada;

\section{Abstract}

Objective: To evaluate the performance of the silkworm when fed mulberry cultivars in different developmental phases. Material and Method: Developed at the Research and Development Unit of the Agência Paulista de Tecnologia dos Agronegócios da Secretaria de Abastecimento e Agricultura do Estado de São Paulo (APTA/SAA), Gália, SP, Brazil, between 12/31/1997 and 05/06/1999. The experiment was started when Bombyx mori L. caterpillars in the $3^{\text {rd }}$ instar, were fed two mulberry cultivars (IZ 56/4 and Korin) in four vegetative phases of development (7, 10, 13 and 16 weeks); in the $5^{\text {th }}$ instar, biological features and cocoon production were analyzed. Results: The analysis of each mulberry cultivar in the different developmental phases showed variations of the biological features caterpillar live weight $(P V)$ and weight gain (GP) only. Among the productive features studied, only the cocoon shell weight (PCS) did vary, when proceeding from caterpillars fed the Korin cultivar. When the two cultivars were compared in each developmental phase, variations were noted only for the biological features $P V$ and chrysalis weight $(P C r)$ and for the productive features cocoon weight (PC), PCS and number of cocoons formed (NC). Conclusions: When leaves of both mulberry cultivars in a developmental phase around 10 weeks were fed to the caterpillars in the $3^{\text {th }}$ and $4^{\text {th }}$ instars, they presented good PV in the $5^{\text {th }}$ instar. However, better GP was observed when they were fed leaves in a more advanced developmental phase (above 10 weeks). There was little influence of treatments on the net silk percentage (PSL) and of the developmental phase of the plant on the NC. In general, the Korin cultivar enabled better biological and productive performance of the silkworm.

Keywords: Animal nutrition. Silkworms, growth and development. Morus. 


\section{Resumen}

Objetivo: Evaluar el desempeño del gusano de seda cuando se le alimenta con variedades de morera en diferentes edades de corte. Material y Método: Desarrollado en la Unidade de Pesquisa e Desenvolvimento de Gália, SP, Brasil, da Agência Paulista de Tecnologia dos Agronegócios da Secretaria de Agricultura e Abastecimento do Estado de São Paulo, en el periodo comprendido entre el 31/12/1997 y el 06/05/1998. El experimento fue iniciado cuando larvas de Bombyx mori L., en el $33^{\circ}$ instar, fueron alimentadas con dos variedades de morera (IZ 56/4 y Korin) en cuatro edades de corte (7, 10, 13 y 16 semanas), analizándose en el 5instar, caracteres biológicos y de producción de capullo. Resultados: Cuando se analizó cada variedad de morera en las diferentes edades de corte, se observaron en sus caracteres biológicos, variaciones solamente para peso vivo (PV) y ganancia de peso (GP) de las larvas. De los caracteres productivos estudiados se observó variación únicamente para peso de cáscara (PCS), cuando provenian de larvas alimentadas con la variedad Korin. Cuando se compararon las variedades en cada edad de corte, solamente se observaron variaciones para los caracteres biológicos $P V$ y peso de pupa (PCr), y para los caracteres productivos, peso de capullo (PC), PCS y número de capullos formados (NC). Conclusiones: Las larvas mostraron buen $P V$ en el $5^{\circ}$ instar, cuando recibieron en el $3^{\circ}$ y $4^{\circ}$ instares, hojas de una y otra variedad de morera con edad de corte próxima a 10 semanas, aunque hubiesen presentado mejor GP al ser alimentadas con hojas de plantas en edad de corte más avanzada (por encima de 10 semanas). La variable porcentaje de seda liquida (PSL) poco fue influenciada por los tratamientos, así como el NC, en relación a la edad de corte de la planta. La variedad Korin en general, proporcionó al gusano de seda mejor desempeño biológico y productivo.

Palabras-clave: Nutrición animal. Gusanos de seda, crecimiento y desarrollo. Morus.

\section{Referências}

1. CHALUVACHARI, T.; BONGALE, U. D. Evaluation of leaf quality of some germaplasm genotypes of mulberry through chemical analysis and biossay with silkworm, Bombyx mori L. Indian Journal of Sericiculture, v. 34, p. 127-132, 1995.

2. LI, R.; SANG, Q. The relationship between quality of mulberry leaves and some economincs characteres during the later larval stage. Science of Sericiculture, v. 10, p. 197-291, 1984.

3. MACHII, H.; KATAGIRI, K. Varietal differences in food value of mulberry leaves with special reference to production efficiency of cocoon shell. Journal of Sericulture Science Japanese, v. 59, p. 34-42, 1990.

4. MENDONÇA, G. A. Utilização de híbridos de amoreira na produção de casulos do bicho-daseda (Bombyx mori L.). Piracicaba, 1994. $59 \mathrm{f}$. Dissertação (Mestrado em Ciências)- Escola Superior de Agricultura "Luiz de Queiroz", Universidade de São Paulo, São Paulo, 1994.
5. NAGATA, M.; KOBAYASHI, M. Quantitative changes in estorage proteins during 1 larval development of the silkworm, Bombyx mori L. Jounal of Sericiculture Science Japanese, v. 59, p. 461-468, 1990.

6. THANGAMANI, R.; VIVEKANANDAN, M. Physiological studies and leaf nutrients analysis in the evaluation of best mulberry variety. Sericologia, La Mulatière, v. 24, p. 317-324, 1984.

7. PANG-CHUAN, W.; DA-CHUANG, C. Silkworm rearing. Rome: Food and Agriculture Organization of the United Nations, 1992. $83 \mathrm{p}$.

8. VOISIN, A. Productividad de la hierba. 3. ed. Madrid: Tecnos, 1971. 499 p.

9. DECHEN, A. R. et al. Absorção de nutrientes pela amoreira Morus Alba L. Anais da Escola Superior de Agricultura "Luiz de Queiroz", v. 30, p. 163173, 1973. 
10. QADER, M. A. et al. Comparative study on the nutritive value of bush, low-cut and tree mulberry leaves at different maturity stages. Sericologia, La Mulatière, v. 31, p. 429-435, 1991.

11. BONGALE, U. D. et al. Leaf nutritive quality associated with maturity levels in fourteen important varieties of mulberry (Morus spp.). Sericologia, La Mulatière, v. 37, p. 71-81, 1997.

12. FONSECA, A. S. et al. Nutrição do bicho-da-seda, Bombyx mori L.: influência da idade da folha sobre o crescimento e desenvolvimento do bicho-daseda. Boletim da Indústria Animal, v. 29, p. 425-433, 1972.

13. hanAdA, Y.; Watanabe, J. K. Manual de criação do bicho-da-seda. Curitiba: Cocamar, 1986. 224 p.

14. MAGÁRIO, K. C. Estudo da composição bromatológica da amoreira (Morus alba L.), variedade Yamada, em várias idades de crescimento. Jaboticabal, 1993. $34 \mathrm{f}$. Monografia (Requisito para a conclusão do Curso de Graduação em Zootecnia)- Faculdade de Ciências Agrárias e Veterinária da Universidade Estadual Paulista, Jaboticabal, 1993.

15. PORTO, A. J. Avaliação do desempenho do bichoda-seda alimentado com clones de amoreira em diferentes estádios de desenvolvimento. Boletim da Indústria Animal, v. 54, p. 81-88, 1997.
16. PORTO, A. J. et al. Effect de quatre clones de Murier (Morus ssp.) a trois estades de developpement sur les caracteristiques du cocon du ver a soie (Bombyx mori L.). Sericologia, La Mulatière, v. 38, p. 347-351, 1998.

17. OKINO, I. Manual de sericicultura. Bauru: [s.n.], 1982. 80p.

18. FONSECA, T. C.; FONSECA, A. S. Cultura da amoreira e criação do bicho-da-seda. São Paulo: Nobel, 1988. 246 p.

19. ISHAAYA, I. Nutritional and allelochemic insectplant interactions relating to digestion and food intake: some examples. In: MILLER, J. R.; MILLER, T. A. Insect-plant interactions. New York: Springer-Verlag, p. 191-223, 1986.

20. PAUL, D. D. et al. Impact of dietary moisture on nutritional indices and growth of Bombyx mori $\mathrm{L}$. and concommitant larval duration. Journal of Insect Physiology, v. 38, p. 229-245, 1952.

21. CROCOMO, W. B.; PARRA, J. R. P. Consumo e utilização de milho, trigo e sorgo por Spodoptera frugiperda (J. E. Smith, 1797) (Lepidoptera, Noctividae). Revista Brasileira de Entomologia, v. 29 , p. $225-260,1985$.

22. PARRA, J. R. P. Consumo e utilização de alimentos por insetos. In: PANIZZI, A. R.; PARRA, J. R. P. Ecologia nutricional de insetos e suas implicações no manejo de pragas. São Paulo: Manole, 1991. p. 9-66.

Endereço / Address / Dirección.

Dr. Antônio José Porto

Unidade de Pesquisa e Desenvolvimento - UPD

Rodovia Eduardo Dias de Castro, Km 1,5 - CP. 16

CEP. 17450000 - Gália, SP, Brasil

Tel./Fax: 0XX (14) 3274-1140

Recebido em: 10/10/2004

E-mail: updgalia@ig.com.br 